\title{
Neurological Problems in COVID-19 Pandemic
}

\author{
Shiv Kumar Saini ${ }^{1} \quad$ Kuljeet Singh Anand ${ }^{1}$ Abhishek Juneja ${ }^{1}$ Rakesh Kumar Mahajan² \\ ${ }^{1}$ Department of Neurology, Dr Ram Manohar Lohia Hospital, \\ New Delhi, India \\ 2Department of Microbiology, Dr Ram Manohar Lohia Hospital, \\ Address for correspondence Kuljeet Singh Anand, DM, Department \\ of Neurology, Dr Ram Manohar Lohia Hospital, New Delhi 110001, \\ India (e-mail: kuljeet_anand@rediffmail.com).
} New Delhi, India

Ann Natl Acad Med Sci (India):2020;56:191-196

\begin{abstract}
Coronavirus disease 2019 (COVID-19) is a potentially severe acute respiratory infection caused by severe acute respiratory syndrome coronavirus 2 (SARS-CoV-2). This outbreak, which emerged in Wuhan city, rapidly spread throughout China and has now become a global public health concern. SARS-CoV-2 is a highly pathogenic and transmissible virus. Common clinical manifestations of COVID-19 include fever, dry cough, shortness of breath, muscle ache, headache, and confusion. Currently, there is no confirmed effective therapeutic strategy for COVID-19 because the pathological mechanism is poorly understood. In addition to the respiratory system involvement, recent evidence has shown that SARS-CoV-2 can affect other organ systems including nervous, vascular, digestive, and urinary system. Various neurological complications have also been described in various studies. Nervous system involvement in the case of SARS-CoV-2 is explained by direct neuro invasion, immune mechanism, and other systemic factors. Neurological complications due to SARS-CoV-2 include both central and peripheral nervous system involvement. Central nervous system complications

Keywords

- neurological

- pandemic

- COVID-19 range from mild headache to seizures, encephalitis, myelitis, and acute cerebrovascular accidents. Peripheral nervous system complications range from vague muscle pains to Guillain-Barré syndrome. This article briefly discusses the various neurological and mental health issues related to COVID-19.
\end{abstract}

\section{Introduction}

Coronavirus disease 2019 (COVID-19) is a potentially severe acute respiratory infection caused by severe acute respiratory syndrome coronavirus 2 (SARS-CoV-2). This outbreak, which emerged in Wuhan city, rapidly spread throughout China and has now become a global public health concern. As of May 21, 2020, globally 48,93,186 cases of COVID-19 have been reported, including 3,23,256 deaths. ${ }^{1}$

The SARS-CoV-2 is from the family of large enveloped nonsegmented positive-sense ribonucleic acid viruses. ${ }^{2}$ SARS-CoV is a respiratory virus, which mutates quickly and causes common cold to severe diseases such as severe acute respiratory syndrome (SARS-CoV, 2002-2004) and Middle East respiratory syndrome (MERS-CoV, 2013-2014). SARS-Cov-2 shares $88 \%$ genetic similarity with SARS-CoV and 50\% resemblance with MERS-CoV. ${ }^{3}$

Clinical manifestations of COVID-19 are fever 83\%, cough $82 \%$, shortness of breath $31 \%$, muscle ache $11 \%$, confusion $9 \%$, headache $8 \%$, and sore throat $5 \%{ }^{4}$ SARS-CoV-2 is highly pathogenic and transmissible virus. ${ }^{5}$ Currently, there is no confirmed effective therapeutic strategy for COVID-19 because the pathological mechanism is poorly understood. In addition to the respiratory system involvement, recent evidence has shown that SARS-CoV-2 can affect other organ systems including nervous, vascular, digestive, urinary, and hematological. ${ }^{4,6}$ The pathological findings established the nature of multiorgan
DOI https://doi.org/ $10.1055 / \mathrm{s}-0040-1717833$ ISSN 0379-038X.
(C) 2020. National Academy of Medical Sciences (India).

This is an open access article published by Thieme under the terms of the Creative Commons Attribution-NonDerivative-NonCommercial-License, permitting copying and reproduction so long as the original work is given appropriate credit. Contents may not be used for commercial purposes, or adapted, remixed, transformed or built upon. (https://creativecommons.org/licenses/by-nc-nd/4.0/).

Thieme Medical and Scientific Publishers Pvt. Ltd. A-12, 2nd Floor, Sector 2, Noida-201301 UP, India 
damage by SARS-CoV-2, which consists of pulmonary lesion and cerebral edema, microvascular steatosis, and thrombosis. ${ }^{7}$ Various neurological complications were also described in various studies from different regions of the world.

Neuropathogenesis: Nervous system involvement in case of SARS-CoV-2 is explained by direct neuroinvasion, immune mechanism, and other systemic factors (hypoxia, thrombosis, metabolic derangements).

\section{Direct Neuroinvasion}

Nervous System Route

SARS-CoV-2 is in the same beta-coronavirus clade as MERS-CoV and SARS-CoV, and shares highly homological sequence with SARS-CoV that has been revealed in the genomic analysis. ${ }^{8}$ The evidence shows that COVID-19 shares similar pathogenesis and receptors for the entry of SARSCoV-2 into human host cells as SARS-CoV..$^{9-11}$ Most CoVs share a similar viral structure and infection pathway and thus the infection mechanisms earlier found for other CoVs may also be applicable for SARS-CoV-2.12,13

The animal and human experimental studies confirmed that either SARS-CoV or MERS-CoV was capable to infect the brain. ${ }^{14}$ Additionally, in one report the SARS-CoV was detected in the cerebrospinal fluid (CSF) of a patient with neurological consequence following SARS infection. ${ }^{15}$ The evidence of angiotensin-converting enzyme 2 (ACE2) expression by the glial cells and neurons in the brain further suggests neurotropism of the SARS-CoV-2. ${ }^{16-20}$

The main transmission of $\mathrm{CoV}$ is through droplet spread; $\mathrm{CoV}$-laden droplets sticking to the nasal mucosa travel to the lungs and also possibly enter central nervous system (CNS) through the olfactory nerve endings. ${ }^{5}$ This hypothesis of CNS invasion through the olfactory nerve endings could also explain the symptom of hyposmia in infected patients. ${ }^{21,22}$

Hypogeusia triggered by SARS-COV-2 infection could result from injury to any of the three cranial nerves-facial, glossopharyngeal nerve, and vagus nerve, which carry the sense of taste to the nucleus of the solitary tract or thalamic nuclei. ${ }^{5}$ There lies a possibility of SARS-CoV-2 reaching the respiratory center from nucleus of the solitary tract due to close proximity, thus causing neurogenic refractory dyspnea. $^{20,23}$

\section{Hematogenous Route}

SARS-CoV-2 fixes to the ACE2 receptor on the alveolar epithelial cells, triggering endothelial damage and entering the blood circulation. ${ }^{5}$ The virus not only infects the epithelial cells but also the resident, infiltrating and circulating immune cells that secrete cytokines and these infected circulating immune cells transport the virus to other organs and may intensify the permeability of the bloodbrain barrier, thereby encouraging the virus to enter the brain and causing viral encephalitis. ${ }^{24}$ Although there is rare evidence that $\mathrm{CoV}$, especially SARS $\mathrm{CoV}$-2, invades the nervous system via the blood circulation pathway, subsequent studies are expected. ${ }^{25,26}$

\section{Digestive Tract Route}

ACE2 receptors are expressed in intestinal epithelial cells also besides alveolar epithelial cells. ${ }^{5}$ The intestinal viral infection causes inflammatory reaction damaging the mucosal barrier, gaining entry into the blood circulation. ${ }^{5,27}$ There is a possibility of retrograde viral entry into the CNS through enteric nervous system. ${ }^{5}$

\section{Lymphatics and/or Cerebrospinal Fluid Route}

The virus may gain entry into the CNS through lymphatic pathway. It is capable of invading the hilar and mesenteric lymph nodes directly, ultimately entering the blood stream and thus spreading to the CNS..$^{28,29}$

\section{Immune Mechanism}

SARS and COVID-19 have led to a large number of mortalities, most of which have been due to multiple organ failure triggered by virus induced systemic inflammatory response syndrome. ${ }^{30,31}$ The ability of the virus to infect macrophages, microglia, and astrocytes in the CNS is principally important. Interleukin- 6 has been correlated with the severity of COVID-19 symptoms. ${ }^{32}$

\section{Miscellaneous}

The virus causes diffuse alveolar and interstitial inflammatory reaction in the lungs causing poor alveolar gas exchange. This in turn may lead to hypoxic damage in the central nervous tissue. ${ }^{33,34}$

SARS-CoV-2 infection is associated with a prothrombotic state producing venous and arterial thromboembolism and elevated D-dimer levels. ${ }^{35}$ Severe COVID-19 is linked with proinflammatory cytokines that induce endothelial and mononuclear cell activation with expression of tissue factor, leading to coagulation activation and thrombin generation and thrombotic tendencies causing ischemic and thrombotic episodes. It has been proposed that COVID-19 might stimulate the production of antiphospholipid antibodies as a mechanism of ischemic stroke. ${ }^{36}$

The biological characteristics of the CNS may enable exacerbation of the neurological damage caused by $\mathrm{CoV}$ infections. The CNS has a dense parenchymal structure and the typical absence of permeability of its blood vessels is a barrier to virus invasion. Nevertheless, if a virus gains access to the CNS, it is hard to eliminate. ${ }^{37}$ Due to the absence of major histocompatibility complex antigens in nerve cells, the removal of viruses in nerve cells depends exclusively on the role of cytotoxic T cells. ${ }^{38}$

\section{Neurological Manifestations}

SARS-CoV-2 is mainly respiratory virus but various neurological manifestations and complications have been described in literature. Although there are plenty of studies and articles available on clinical features of COVID-19, dedicated studies on neurological manifestations are scarce. Available literature is summarized in - Table $\mathbf{1}$.

Mao et al studied 214 patients of COVID-19 from China and of these, 78 (36.4\%) had various neurologic manifestations. Seventy-eight patients (36.4\%) had nervous system 
manifestations: CNS (53 [24.8\%]), peripheral nervous system (PNS) (19 [8.9\%]), and skeletal muscle injury (23 [10.7\%]). In CNS manifestations, the most common symptoms were dizziness (36 [16.8\%]) and headache (28 [13.1\%]). In patients with PNS involvement, the common symptoms were taste impairment (12 [5.6\%]) and smell impairment (11 [5.1\%]). ${ }^{39}$

The patients with severe infection were relatively older ( 58.2 vs. 48.9 years) and had underlying disorders particularly hypertension (36.4 vs. $15.1 \%$ ), and lack of typical clinical symptoms such as fever (45.5 vs. $73 \%$ ) and dry cough (34.1 vs. $61.1 \%$ ). ${ }^{39}$

Furthermore, nervous system manifestations were significantly more common in severe infections compared with nonsevere infections ( 45.5 vs $30.2 \%$ ). ${ }^{39}$

Helms et al described the neurologic features in an observational series of 58 of 64 consecutive patients admitted to intensive care unit (ICU) due to acute respiratory distress syndrome following SARS-CoV-2 infection. Neurological complications were seen in 49/58 (84\%) patients. As evaluated by confusion assessment method for ICU scale, agitation was the most common symptom 40/58 (69\%) followed by confusion 26/40 (65\%). Diffuse corticospinal tract signs with exaggerated tendon reflexes and bilateral extensor plantar reflexes were seen in 39 patients (67\%). Of the patients who had been discharged, 15 of 45 (33\%) had dysexecutive syndrome consisting of inattention, disorientation, or poorly organized movements in response to command. Two asymptomatic patients each had a small acute ischemic stroke and one patient had a subacute ischemic stroke. ${ }^{40}$

Li et al studied 221 consecutive hospitalized patients with COVID-19 infection. They found that 11 (5\%) patients developed acute ischemic stroke, one $(0.5 \%)$ developed cerebral venous sinus thrombosis, and one (0.5\%) developed intracerebral hemorrhage. The mean age of patients who developed stroke ( 72 years) was higher ( 52 years). Of the 11 patients with ischemic stroke, five were associated with large artery disease, three with small artery disease, and other three with cardioembolic events. The fibrin D-dimer levels were 12 -fold higher in patients who developed stroke demonstrating a hypercoagulable state. ${ }^{41}$

Yang et al did a retrospective, observational study and enrolled 52 critically ill adult patients with SARSCoV-2 pneumonia who were admitted to the ICU in Wuhan, China, and found headache in $6 \%$ of the patients. ${ }^{42}$

\section{Central Nervous System}

\section{Cerebrovascular Accidents}

Mao et al described six cases of cerebrovascular accident (CVA) in their cohort of 214 patients. There were five cases of ischemic and one case of hemorrhagic stroke. ${ }^{39}$ The French cohort had three cases of ischemic strokes that were detected on neuroimaging when the patients undertook imaging for encephalopathy. ${ }^{40}$ In a study by Li et al., the incidence of

Table 1 Neurological manifestations in COVID-19 as described in various studies

\begin{tabular}{|c|c|c|c|c|}
\hline S.N. & Authors/year & Study population & \multicolumn{2}{|c|}{ Neurological manifestations } \\
\hline \multirow[t]{4}{*}{1.} & $\begin{array}{l}\text { Mao et al }\left.\right|^{39} \\
(2020)\end{array}$ & 214 admitted patients (China) & CNS involvement (24.8\%) & $\begin{array}{l}\text { Dizziness: } 16.8 \% \\
\text { Headache: } 13.1 \% \text { Impaired } \\
\text { consciousness: } 7.5 \% \\
\text { Acute CVA: } 2.8 \% \\
\text { Ataxia: } 0.5 \%\end{array}$ \\
\hline & & & & Seizure: $0.5 \%$ \\
\hline & & & PNS involvement $(8.9 \%)$ & $\begin{array}{l}\text { Taste impairment: } 5.6 \% \\
\text { Smell impairment: } 5.1 \% \\
\text { Vision impairment: } 1.4 \% \\
\text { Nerve pain: } 2.3 \%\end{array}$ \\
\hline & & & $\begin{array}{l}\text { Skeletal muscular } \\
\text { manifestations (10.7\%) }\end{array}$ & Muscle pain \\
\hline 2 & $\begin{array}{l}\text { Helms et al }{ }^{40} \\
(2020)\end{array}$ & $\begin{array}{l}\text { Case series of } 58 \text { patients } \\
\text { (France) }\end{array}$ & \multicolumn{2}{|c|}{$\begin{array}{l}\text { Agitation in } 69 \% \text {, confusion in } 65 \% \text {, corticospinal tract signs } \\
\text { in } 67 \% \text {, dysexecutive syndrome in } 36 \%\end{array}$} \\
\hline 3 & $\begin{array}{l}\text { Li et al }\left.\right|^{41} \\
(2020)\end{array}$ & $\begin{array}{l}\text { Case series of } 221 \text { admitted } \\
\text { Patients (China) }\end{array}$ & \multicolumn{2}{|c|}{$\begin{array}{l}\text { Acute ischemic stroke in } 5 \% \text {, cerebral venous sinus thrombosis } \\
\text { in } 0.5 \% \text {, cerebral hemorrhage in } 0.5 \%\end{array}$} \\
\hline 4 & $\begin{array}{l}\text { Yang et al }{ }^{42} \\
(2020)\end{array}$ & $\begin{array}{l}52 \text { critically ill adult patients } \\
\text { (China) }\end{array}$ & \multicolumn{2}{|l|}{ Headache in $6 \%$} \\
\hline 5 & $\begin{array}{l}\text { Wang et } a^{43} \\
(2020)\end{array}$ & $\begin{array}{l}\text { Case series of } 138 \text { hospitalized } \\
\text { patients (China) }\end{array}$ & \multicolumn{2}{|c|}{ Dizziness in $9 \%$; headache in $7 \%$} \\
\hline 6 & $\begin{array}{l}\text { Toscano et al }{ }^{56} \\
(2020)\end{array}$ & Case series of 5 patients (Italy) & \multicolumn{2}{|c|}{ Flaccid areflexic limb weakness in $80 \%$, facial weakness in $60 \%$} \\
\hline 7 & $\begin{array}{l}\text { Lechien et al }{ }^{59} \\
(2020)\end{array}$ & $\begin{array}{l}417 \text { patients (Belgium, France, } \\
\text { Italy, Spain, and Switzerland) }\end{array}$ & \multicolumn{2}{|c|}{ Smell dysfunction in $86 \%$, taste dysfunction in $82 \%$} \\
\hline
\end{tabular}


stroke in COVID-19 patients was $~ 5 \%$ and they postulated elevated levels of C-reactive protein and D-dimer, indicative of an inflammatory state and irregularities with the coagulation cascade, respectively, which might play a part in the pathophysiology of stroke in COVID-19 infection. ${ }^{41}$

Sharifi-Razavi et al described a case of intracranial bleeding ensuing in CVA in a 79-year-old COVID-19-positive male who was neither a known hypertensive nor on any anticoagulants that could have caused this event. ${ }^{44}$ The authors postulated that probably dysregulation in the ACE2 receptors leading to cerebral autoregulation disruption and high blood pressure spikes resulted in arterial wall rupture.

\section{Encephalitis}

Moriguchi et al described first confirmed case of COVID-19-related viral encephalitis from Japan. ${ }^{45} \mathrm{~A}$ 24-yearold man presented with headache and fever followed by seizure and episode of unconsciousness. He had neck stiffness; computed tomographic (CT) scan of brain was unremarkable. Cerebrospinal fluid reverse transcription-polymerase chain reaction (CSF RT-PCR) detected SARS-CoV-2. Brain magnetic resonance imaging (MRI) revealed diffusion restriction along the wall of inferior horn of right lateral ventricle, and fluid-attenuated inversion recovery images showed hyperintense signal changes in the right mesial temporal lobe and hippocampus suggestive of encephalitis. ${ }^{45}$

Huang et al reported a case of 40-year-old woman from United States who presented with fever followed by syncope and nasopharyngeal swab on admission was positive for SARS-CoV-2 and afterward CSF was found to be positive for SARS-CoV-2 as well. ${ }^{46}$

\section{Acute Hemorrhagic Necrotizing Encephalopathy}

Poyiadji et al described a case of a female patient in her late fifties, presenting with a 3-day history of cough, fever, and altered mental status and subsequently the diagnosis of COVID-19 made by RT-PCR of nasopharyngeal swab specimen. ${ }^{47}$ In this case, testing for the presence of SARS-CoV-2 in the CSF was not done. Noncontrast head CT images demonstrated symmetric hypoattenuation within bilateral medial thalami with a normal CT angiogram and CT venogram. Brain MRI demonstrated hemorrhagic rim enhancing lesions within the bilateral thalami, medial temporal lobes, and subinsular regions. Authors suggested this patient might have a cytokine storm syndrome due to severe COVID-19 that resulted in blood-brain barrier breakdown leading to this presentation.

\section{Acute Myelitis}

Zhao et al described a case of 66-year-old male form Wuhan city, China, who was admitted for fever and fatigue of 2 days without cough; later on he developed acute flaccid paraparesis with sensory level at T-10 and urinary and bowel incontinence. ${ }^{48}$ All other microbiological studies were negative except for SARS-CoV-2 nucleic acid testing in nasopharyngeal swab. Authors suggested clinical findings could be ascribed to a postinfectious acute myelitis. ${ }^{48}$
Sarma and Bilello reported a case of 28-year-old female who tested positive for COVID-19 via RT-PCR of nasopharyngeal swab and later on diagnosed as longitudinally extensive acute transverse myelitis. ${ }^{49}$

\section{Encephalopathy}

Chen et al in a retrospective study of the clinical characteristics of 113 COVID-19 patients from China documented hypoxic encephalopathy in 20 patients. ${ }^{50}$ The incidence was significantly lower in the patients who had recovered. Mao et al described impaired consciousness in 16 (7.5\%) patients in their cohort but the diagnostic criteria used were not well-defined. ${ }^{39}$ Filatov et al reported a case of a 74-year-old male with multiple comorbidities who developed altered mental status after headache, fever, and cough. ${ }^{51}$

\section{Seizures}

Vollonoet al described a case of 78-year-oldSARS-CoV-2-positive female patient, who was admitted for focal status epilepticus without any prodromal symptoms in the form of myoclonic jerks of the right side of face and right-sided limbs..$^{52}$ The electroencephalogram discovered semirhythmic, irregular, high amplitude delta activity, mainly lateralized over the left fronto-centro-temporal regions, consistent with focal status epilepticus.

Sohal and Mansur also reported a case of 72-year-old man with comorbidities, who was noted to have multiple episodes of tonic clonic movements of his upper and lower extremities. $^{53}$

\section{Headache and Dizziness}

Headache and dizziness have been reported as minor symptoms associated with presentation of COVID-19 in different studies. The incidence of headache ranges from 6 to 13.1\% and dizziness from 9 to $16.8 \%$ but the detailed mechanism and pathogenesis have not been discussed. ${ }^{39,42,43}$

\section{Peripheral Nervous System}

\section{Olfactory and Gustatory Impairment}

Mao et al reported occurrence of taste impairment (12 [5.6\%]) and smell impairment (11 [5.1\%]) in their 214 patients cohort. ${ }^{39}$ Bagheri et al described that anosmia and hyposmia were seen in $48.23 \%$ of the respondents, while $83.38 \%$ also had a decreased taste sensation. ${ }^{54}$

\section{Guillain-Barré Syndrome}

Many cases of Guillain-Barré syndrome (GBS) are now reported that are related to COVID-19. Zhao et al reported a case of 61-year-old Chinese female patient who presented with acute weakness in both legs and severe fatigue. The diagnosis of GBS was made on the basis of clinical examination and electrophysiological studies. She was treated with intravenous immunoglobulin. A week following this, patient developed dry cough and fever; oropharyngeal 
swab detected SARS-CoV-2 on RT-PCR assay. Hence, GBS related to SARS-CoV-2 might follow the pattern of a parainfectious profile, instead of the classic postinfectious profile. $^{55}$

Toscano et al reported five patients of GBS with COVID-19. The first symptoms of GBS were lower-limb weakness and paresthesia in four patients and facial diplegia followed by ataxia and paresthesia in one patient. After examination and proper investigation (nerve conduction and CSF studies), GBS was diagnosed and treated accordingly..$^{56}$

Overall, these case reports only propose a likely association between GBS and SARS-CoV-2 infection, and more cases with epidemiological data are needed to support a causal relationship.

\section{Skeletal Muscle Damage}

Mao et al reported skeletal muscle injury in 23 of their patients that is $10.7 \%$ of cohort. ${ }^{39}$ Compared with the patients without muscle injury, patients with muscle injury had significantly higher levels of creatine kinase (median, $400.0 \mathrm{U} / \mathrm{L}$ vs. median, $58.5 \mathrm{U} / \mathrm{L}$ ), irrespective of their severity. They have seen that patients with muscle injury had higher neutrophil counts, lower lymphocyte counts, higher C-reactive protein levels, and higher D-dimer levels.

\section{Other Manifestations}

Mao et al also described neuralgia in five patients and ataxia in one, but further details were not mentioned. ${ }^{39}$ Isolated cases of oculomotor nerve paralysis, Miller Fisher syndrome, and polyneuritis cranialis were also described. ${ }^{57,58}$

\section{Conclusion}

Although COVID-19 is mainly a disease of respiratory system, neuropsychological involvement is not uncommon. Neurological manifestations are more in severely ill patients and in some cases can even precede the respiratory symptoms or may be the only symptoms in COVID-19 patients. At present, the full clinical spectrum of patients with COVID-19 with neurological symptoms remains to be categorized. So, there is further need of focused studies.

\section{Conflict of Interest}

None declared.

\section{References}

1 WHO Coronavirus disease. 2019 (COVID-19). Situation Report-41. Available at: https://www.who.int/docs/defaultsource/coronaviruse/situation-reports/20200521-covid-19-sitrep-122.pdf?sfvrsn=24f20e05_2.. Accessed March 3, 2020

2 Pang J, Wang MX, Ang IYH, et al. Potential rapid diagnostics, vaccine and therapeutics for 2019 novel coronavirus (2019-nCoV): a systematic review. J Clin Med 2020;9(3):623

3 Li X, Geng M, Peng Y, Meng L, Lu S. Molecular immune pathogenesis and diagnosis of COVID-19. J Pharm Anal 2020;10(2):102-108
4 Chen N, Zhou M, Dong X, et al. Epidemiological and clinical characteristics of 99 cases of 2019 novel coronaviruspneumoniain Wuhan, China: a descriptive study. Lancet 2020;395(10223):507-513

5 Li Z, Liu T, Yang N, et al. Neurological manifestations of patients with COVID-19: potential routes of SARS-CoV-2 neuroinvasion from the periphery to the brain. Front Med 2020. Doi: 10.1007/s11684-020-0786-5

6 Huang C, Wang Y, Li X, et al. Clinical features of patients infected with 2019 novel coronavirus in Wuhan, China. Lancet 2020;395(10223):497-506

$7 \mathrm{Xu} \mathrm{Z}$, Shi L, Wang Y, et al. Pathological findings of COVID-19 associated with acute respiratory distress syndrome. Lancet Respir Med 2020;8(4):420-422

8 Yu F, Du L, Ojcius DM, Pan C, Jiang S. Measures for diagnosing and treating infections by a novel coronavirus responsible for a pneumonia outbreak originating in Wuhan, China. Microbes Infect 2020;22(2):74-79

9 Song Z, Xu Y, Bao L, et al. From SARS to MERS, thrusting coronaviruses into the spotlight. Viruses 2019;11(1):59

10 Lu R, Zhao X, Li J, et al. Genomic characterisation and epidemiology of 2019 novel coronavirus: implications for virus origins and receptor binding. Lancet 2020;395(10224):565-574

11 Wan Y, Shang J, Graham R, Baric RS, Li F. Receptor recognition by the novel coronavirus from Wuhan: an analysis based on decade-long structural studies of SARS coronavirus. J Virol 2020;94(7):e00127-e20

12 Yuan Y, Cao D, Zhang Y, et al. Cryo-EM structures of MERS-CoV and SARS-CoV spike glycoproteins reveal the dynamic receptor binding domains. Nat Commun 2017;8:15092

13 Hulswit RJ, de Haan CA, Bosch BJ. Coronavirus spike protein and tropism changes. Adv Virus Res 2016;96:29-57

14 Paybast S, Emami A, Koosha M, Baghalha F. Novel coronavirus disease (COVID-19) and central nervous system complications: what neurologist need to know. Acta Neurol Taiwan 2020;29(1):24-31

15 Lau KK, Yu WC, Chu CM, Lau ST, Sheng B, Yuen KY. Possible central nervous system infection by SARS coronavirus. Emerg Infect Dis 2004;10(2):342-344

16 Zhao Y, Zhao Z, Wang Y, et al. Single-Cell RNA expression profiling of ACE2, the putative receptor of Wuhan 2019-nCoV. bioRxiv 2020. Doi: 10.1101/2020.01.26.919985

17 Kuhn JH, Li W, Choe H, Farzan M. Angiotensin-converting enzyme 2: a functional receptor for SARS coronavirus. Cell Mol Life Sci 2004;61(21):2738-2743

18 Qian Z, Travanty EA, Oko L, et al. Innate immune response of human alveolar type II cells infected with severe acute respiratory syndrome-coronavirus. Am J Respir Cell Mol Biol 2013;48(6):742-748

19 Lu G, Hu Y, Wang Q et al. Molecular basis of binding between novel human coronavirus MERS-CoV and its receptor CD26. Nature 2013;500(7461):227-231

20 Baig AM, Khaleeq A, Ali U, Syeda H. Evidence of the COVID-19 virus targeting the CNS: tissue distribution, host-virus interaction, and proposed neurotropic mechanisms. ACS Chem Neurosci 2020;11(7):995-998

21 Li K, Wohlford-Lenane C, Perlman S, et al. Middle East respiratory syndrome coronavirus causes multiple organ damage and lethal disease in mice transgenic for human dipeptidyl peptidase 4. J Infect Dis 2016;213(5):712-722

22 Netland J, Meyerholz DK, Moore S, Cassell M, Perlman S. Severe acute respiratory syndrome coronavirus infection causes neuronal death in the absence of encephalitis in mice transgenic for human ACE2. J Virol 2008;82(15):7264-7275

23 Li YC, Bai WZ, Hashikawa T. The neuroinvasive potential of SARS-CoV2 may play a role in the respiratory failure of COVID-19 patients. J Med Virol 2020;92(6):552-555 
24 Unni SK, Růžek D, Chhatbar C, Mishra R, Johri MK, Singh SK. Japanese encephalitis virus: from genome to infectome. Microbes Infect 2011;13(4):312-321

25 Koyuncu OO, Hogue IB, Enquist LW. Virus infections in the nervous system. Cell Host Microbe 2013;13(4):379-393

26 Desforges M, Le Coupanec A, Dubeau P, et al. Human coronaviruses and other respiratory viruses: underestimated opportunistic pathogens of the central nervous system? Viruses 2019;12(1):14

27 Romani L, Del Chierico F, Chiriaco M, et al. Gut mucosal and fecal microbiota profiling combined to intestinal immune system in neonates affected by intestinal ischemic injuries. Front Cell Infect Microbiol 2020;10:59

28 Zhao JM, Zhou GD, Sun YL, et al. [Clinical pathology and pathogenesis of severe acute respiratory syndrome]. Zhonghua Shi Yan He Lin Chuang Bing Du Xue Za Zhi 2003;17(3):217-221

29 Cashion MF, Banks WA, Bost KL, Kastin AJ. Transmission routes of HIV-1 gp120 from brain to lymphoid tissues. Brain Res 1999;822(1-2):26-33

30 Yin $\mathrm{CH}$, Wang C, Tang Z, Wen Y, Zhang SW, Wang BE. [Clinical analysis of multiple organ dysfunction syndrome in patients suffering from SARS]. Zhongguo Wei Zhong Bing Ji Jiu Yi Xue 2004;16(11):646-650

31 Chen C, Zhang XR, Ju ZY, He, WF. [Advances in the research of mechanism and related immunotherapy on the cytokine storm induced by coronavirus disease 2019]. Zhonghua Shao Shang Za Zhi 2020;36(0):471-475

32 Wan S, Yi Q, Fan S, et al. Characteristics of lymphocyte subsets and cytokines in peripheral blood of 123 hospitalized patients with 2019 novel coronavirus pneumonia (NCP). Medrxiv 2020. Doi 10.1101/2020.02.10.20021832

33 Abdennour L, Zeghal C, Dème M, Puybasset L. Interaction cerveau-poumon. [Interaction brain- lungs] Ann Fr Anesth Reanim 2012;31(6):e101-e107

34 Guo YR, Cao QD, Hong ZS, et al. The origin, transmission and clinical therapies on coronavirus disease 2019 (COVID-19) outbreak - an update on the status. Mil Med Res 2020;7(1):11

35 Tang N, Li D, Wang X, Sun Z. Abnormal coagulation parameters are associated with poor prognosis in patients with novel coronavirus pneumonia. J Thromb Haemost 2020;18(4):844-847

36 Zhang Y, Xiao M, Zhang S, et al. Coagulopathy and antiphospholipid antibodies in patients with Covid-19. N Engl J Med 2020;382(17):e38

37 Reinhold AK, Rittner HL. Barrier function in the peripheral and central nervous system-a review. Pflugers Arch 2017;469(1):123-134

38 Wüthrich C, Batson S, Koralnik IJ. Lack of major histocompatibility complex class I upregulation and restrictive infection by JC virus hamper detection of neurons by T lymphocytes in the central nervous system. J Neuropathol Exp Neurol 2015;74(8):791-803

39 Mao L, Jin H, Wang M, et al. Neurologic manifestations of hospitalized patients with coronavirus disease 2019 in Wuhan, China. JAMA Neurol 2020:e201127

40 Helms J, Kremer S, Merdji H, et al. Neurologic features in severe SARS-CoV-2 infection. N Engl J Med 2020;382(23):2268-2270

41 Li Y, Li M, Wang M, et al. Acute cerebrovascular disease following COVID-19: a single center, retrospective, observational study. Stroke Vasc Neurol 2020;5(3):279-284
42 Yang X, Yu Y, Xu J, et al. Clinical course and outcomes of critically ill patients with SARS-CoV-2 pneumonia in Wuhan, China: a single-centered, retrospective, observational study. Lancet Respir Med 2020;8(5):475-481

43 Wang D, Hu B, Hu C, et al. Clinical characteristics of 138 hospitalized patients with 2019 novel coronavirus-infected pneumonia in Wuhan, China. JAMA 2020;323(11):1061-1069

44 Sharifi-Razavi A, Karimi N, Rouhani N. COVID-19 and intracerebral haemorrhage: causative or coincidental? New Microbes New Infect 2020;35:100669

45 Moriguchi T, Harii N, Goto J, et al. A first case of meningitis/ encephalitis associated with SARS-Coronavirus-2. Int J Infect Dis 2020;94:55-58

46 Huang YH, Jiang D, Huang JT. SARS-CoV-2 detected in cerebrospinal fluid by PCR in a case of COVID-19 encephalitis. Brain Behav Immun 2020;87:149

47 Poyiadji N, Shahin G, Noujaim D, et al. COVID-19-associated acute hemorrhagic necrotizing encephalopathy: CT and MRI features. Radiology 2020;296(2):E119-E120

48 Zhao K, Huang J, Dai D, et al. Acute myelitis after SARSCoV-2 infection: a case report. Medrxiv 2020. Doi: 10.1101/ 2020.03.16.20035105

49 Sarma D, Bilello LA. A case report of acute transverse myelitis following novel coronavirus infection. Clin Pract Cases Emerg Med 2020;4(3)321-323

50 Chen $\mathrm{T}, \mathrm{Wu} \mathrm{D}$, Chen $\mathrm{H}$, et al. Clinical characteristics of 113 deceased patients with coronavirus disease 2019: retrospective study. BMJ 2020;368:m1091

51 Filatov A, Sharma P, Hindi F, Espinosa PS. Neurological complications of coronavirus disease (COVID-19): encephalopathy. Cureus 2020;12(3):e7352

52 Sohal S, Mansur M. COVID-19 presenting with seizures. IDCases 2020;20:e00782

53 Vollono C, Rollo E, Romozzi M, et al. Focal status epilepticus as unique clinical feature of COVID-19: A case report. Seizure 2020;78:109-112

54 Bagheri SHR, Asghari AM, Farhadi M, et al. Coincidence of COVID-19 epidemic and olfactory dysfunction outbreak. Medrxiv 2020. Doi: 10.1101/2020.03.23.20041889

55 Zhao H, Shen D, Zhou H, Liu J, Chen S. Guillain-Barré syndrome associated with SARS-CoV-2 infection: causality or coincidence? Lancet Neurol 2020;19(5):383-384

56 Toscano G, Palmerini F, Ravaglia S, et al. GuillainBarré syndrome associated with SARS- CoV-2. N Engl J Med 2020;382(26):2574-2576

57 Wei H, Yin H, Huang M, Guo Z. The 2019 novel coronavirus pneumonia with onset of oculomotor nerve palsy: a case study. J Neurol 2020;267(5):1550-1553

58 Gutiérrez-Ortiz C, Méndez-Guerrero A, Rodrigo-Rey S, et al. Miller Fisher syndrome and polyneuritis cranialis in COVID-19. Neurology 2020;95(5):e601-e605

59 Lechien JR, Chiesa-Estomba CM, De Siati DR, et al. Olfactory and gustatory dysfunctions as a clinical presentation of mild-to-moderate forms of the coronavirus disease (COVID19): a multicenter European study. Eur Arch Otorhinolaryngol 2020;277(8):2251-226 